\title{
XII. On the electricity of effluent steam. No. II
}

\section{Wm. Geo. Armstrong Esq.}

To cite this article: Wm. Geo. Armstrong Esq. (1841) XII. On the electricity of effluent steam. No. II, Philosophical Magazine Series 3, 18:114, 50-57, DOI: $10.1080 / 14786444108650243$

To link to this article: http://dx.doi.org/10.1080/14786444108650243

册 Published online: 01 Jun 2009.

Submit your article to this journal 준

Џ Article views: 5

Q View related articles $₫$ 
$50 \mathrm{Mr}$. W. G. Armstrong on the Electricity of Effluent Steam.

To obtain a satisfactory result, we ought to dissolve a somewhat larger quantity of potassium in the alcohol, and employ a still more energetic electric current, and foils approached to one another in the same plane, when the quantities of hydrogen liberated from the two fluids will be found to be very nearly equal in amount; and the comparison is best instituted during the early stages of the action, because the potash gets saturated with the secondary products of oxidation, and the conducting power diminishes, whilst the electric energy is also on the decline.

I still consider the experiments, now and formerly detailed, to afford the only direct experimental proof which we yet have of the existence of water, as such, in absolute alcohol. The oxidation of potassium in alcohol, with evolution of hydrogen, is perhaps the nearest approach of other experiments to such evidence; but still the tendency to form æether, and the affinity of potash for that substance, might give rise to the evolution of hydrogen. But it appears to be quite impossible, on electro-chemical principles, to suppose, that under electric agency a part of the hydrogen of the alcohol should go to one pole, and the remainder, with its other constituents, to the other, there being no evidence of any one substance at the positive pole, which could have been in combination with hydrogen as an electrolytic compound; and, besides, we have direct proof that it is oxygen which passes to the positive pole, because the effects which take place there are effects of oxidation, and under particular arrangements that oxygen becomes even visible. We have thus oxygen going to the one pole and hydrogen to the other, and the latter in the proportion in which it exists in water; and it is only a truism to say that the direct voltaic decomposition of any substance cannot take place, unless that substance previously has a distinct and substantive existence.

XII. On the Electricity of Effuent Steam. No. II. By W. G. Armstrong, Esq.

To the Editors of the Philosophical Magazine and Journal. Gentlemen,

T concluding my last communication on the above subject*, I alluded to experiments which had then been commenced to try the effect of insulating the boiler and entirely condensing the issuing steam. These experiments have since been completed, and many others have also been tried which subsequently suggested themselves, all of which I shall now proceed to describe.

* See our last Number, vol. xvii., p. 452. 
The insulation of the boiler was effected by lifting the engine with screw-jacks, until the wheels were raised about six inches above the rails, and then supporting it upon four insulators which rested upon logs of timber. Each insulator consisted of three separate pieces of baked wood, coated with pitch, and having layers of pitch and brown paper placed between them. The middle piece was made larger than the other two, so as to project beyond them, and thereby increase the surface without adding to the height of the insulator, which would have been dangerous; and the three pieces when put together formed a block, of which a representation is annexed (fig. 1.).

As soon as the engine was placed on the insulators, the boiler was filled with water, and the fire lighted, and as the pressure gradually rose in the boiler, the steam was occasionally suffered to escape.

The engine indicated no electricity whatever so long as the steam was confined in the boiler, but became negatively electriFig. 1. fied as soon as any escape was permitted. A very trifling escape proved sufficient to render the negative electricity of the boiler sensible, and when the steam was very freely discharged the negative development became exceedingly powerful. The sparks never much exceeded an inch in length, but were very large and brilliant, and, owing no doubt to the magnitude of the body from which they were drawn, they produced effects fully equal to those obtained by the use of an average-sized Leyden jar. Some idea of their potency may be formed from the fact, that when not more than half an inch in length, they easily ignited a piece of cotton wool flled with powdered resin.

The greatest care was taken to ascertain whether the extent of the electrical development was at all dependent upon the density of the steam in the boiler; and it was found that when the discharge from the valve was so regulated in the different trials as to render the actual quantity or weight of steam ejected in a given time as uniform as possible, the ne. gative electricity of the boiler increased a little with the pressure, but the positive electricity, drawn by the pointed conductor from the issuing steam, increased enormously as the density of the steam was augmented. After the fire had been extinguished at the close of the experiments, and the pressure had subsided to six or eight pounds on the square inch, sparks E 2 
could no longer be obtained from the conductorheld in the steam, but the negative electricity of the boiler continued to produce sparks until the steam was entirely exhausted, or as nearly so as possible. These results appear to indicatethat a jet of high-pressure steam is not in reality much more electrical than one of low-pressure steam, but merely that the electricity of the high-pressure jet is more easily collected.

The insulation of the boiler undoubtedly had the effect of diminishing the positive electricity obtained from the steam, but not to such an extent as might have been anticipated.

A glass tube $\mathbf{A}$ (fig. 2), with a cock $\mathrm{C}$ affixed to it, having been inserted in the boiler in the manner described in my last letter, another glass tube B, about four feet long, was attached to the cock, and supported at the end furthest from the boiler by a glass rod fixed in the insulating stool. A small brass cylinder $\mathrm{D}$ having a number of pointed wires projecting from one end into the inside, as shown in the section (fig. 3),

Fig. 2.

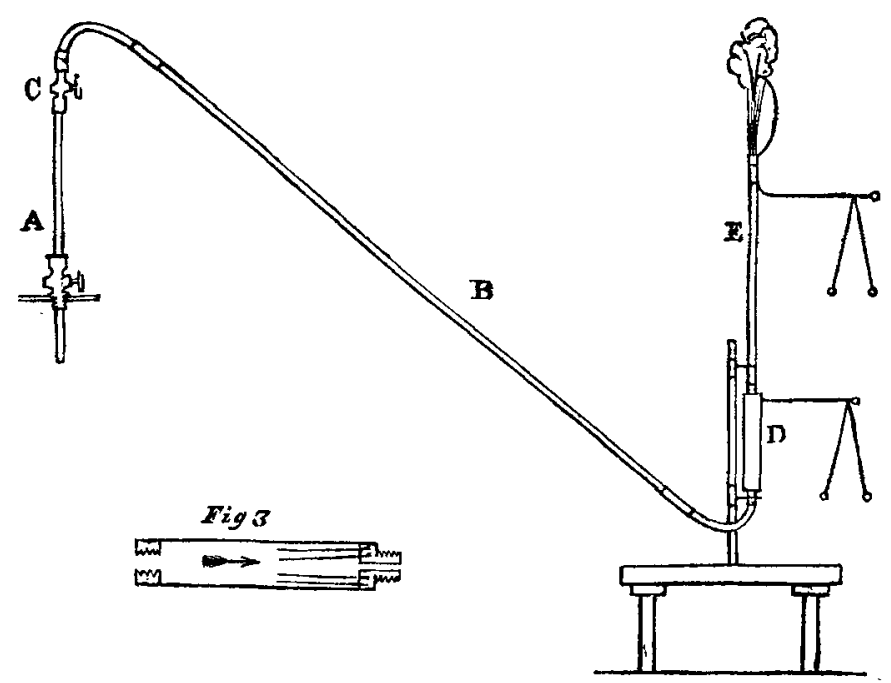

was then joined to the glass tube $B$, and to this cylinder was added a third glass tube $E$, so as to extend the channel through which the steam was to be conveyed. A wire with forked points was affixed to the top of the tube $E$ for the purpose of collecting the electricity of the jet, and from this wire a pair of pith-balls was suspended. Another pair of pith-balls was in like manner suspended from a wire screwed into the brass cylinder, all which arrangements will be clearly understood 
by reference to the figure. The cyiinder, and a great part of each of the tubes, were enveloped in flannel, so as to prevent condensation as much as possible. The chief object of this apparatus was to test the electrical condition of the steam before it issued into the air, both when the boiler was insulated and when it was connected by a conductor with the earth. An iron bar was then placed against the engine to establish a communication between it and the ground, and the cock being opened, a current of steam mixed with water issued from the tube E. Under these circumstances both pairs of balls remained stationary, the electricity being probably carried off by the water which escaped with the steam. As the tubes became heated the quantity of water discharged with the steam was reduced to a mere spray, and both pairs of balls then slightly diverged with positive electricity, the upper pair expanding rather more than the lower pair; but upon partially closing the cock both pairs of balls expanded fully three times as much as they had done when the cock was fully open; and then gradually converged, arriving at their original position after the lapse of about a minute.

I was at first exceedingly puzzled how to account for this singular effect of attenuating the steam, but 1 now think it may be explained as follows. It is probable that the moisture of the steam when the cock is fully open is sufficient to enable it to conduct great part of the electricity of the jet back again to the boiler; but that as soon as the temperature of the steam is reduced by the attenuation below the temperature which the tubes have previously acquired from the high-pressure steam, its dryness is so far increased as to prevent the transmission of electricity from the jet to the boiler, but not from the jet to the cylinder, which is a much nearer object. As the tubes cool down to an equality with the steam the dampness returns, and the electricity is again in a great measure carried back to the boiler.

The iron bar was then removed from its contact with the boiler so as to restore the insulation, and the engine was rendered intensely negative by a copious emission of steam from the safety-valve. The cock being again fully opened, both pairs of balls diverged strongly with negative electricity; and by diminishing the escape from the valve to a certain point, and then partly closing the cock, the upper balls indicated positive, and the lower ones negative electricity. When the escape from the valve was entirely prevented and the cock fully opener, both pairs of balls remained in a collapsed state, but on partly opening the cock they both diverged for a short time with positive electricity to much the same extent as they 


\section{Mr. W. G. Armstrong on the Electricity of Effluent Steam.}

had previously done while the boiler communicated with the earth by means of the iron bar.

It is important to state that when the balls were repelled with negative electricity, they collapsed very considerably when the cock was touched by the hand, but when they diverged with positive electricity no effect was produced by touching the cock, which strongly favours the supposition that the positive electricity manifested by the lower pith-balls, was conducted to the cylinder from the jet.

A coil of lead pipe, immersed in a glas jar filled with wet snow, was then placed upon the insulating stool and connected with the tube $B$, after the brass cylinder had been detached; and the iron bar was again placed against the boiler to suspend the insulation. Upon opening the cock to the full extent, little or no electricity could be discovered in the coil, but when the cock was partly closed, positive electricity appeared for a short time and then faded away exactly as in the experiments with the brass cylinder. Upon removing the connexion between the boiler and the earth and raising the valve the coil became highly negative, but upon closing the valve the negative electricity vanished.

I have little doubt that the predominance of the negative over the positive electricity in the above experiment is attributable to the conducting power of the steam causing more negative electricity to be conveyed to the coil from the boiler, than the coil would acquire if the steam were a non-conductor. When negative electricity was in like manner so strongly manifested by the pith-balls in the experiments with the brass cylinder, it was noticed, that after closing the cock, while the interior of the tubes were bedewed with moisture, scarcely any negative electricity was transmitted to the balls, so that the conducting power must have been in the steam, and not in the mere dampness on the glass.

A vertical glass tube, about an inch in diameter, and between two and three feet long, was then screwed on to the cock in substitution of the tube $B$. The lower part of this tube contained a number of pointed wires for the purpose of abstracting and imparting to the cock any electricity which the steam might possess on entering the tube. When the cock was now fully opened, flashes of light began to dart through the whole length of the tube, from the cloud above it to the cock, and continued to do so as long as the cock remained open, both when the boiler was insulated, and when it was connected with the earth. The steam in the tube was perfectly transparent, and no moisture could be seen on the inner surface of the glass. 
The visible transmission of electricity from the jet to the cock, in this experiment, furnishes convincing proof that the positive electricity which we find in the jet is not developed until the steam assumes the form of a visible vapour; and it shows also that the steam, even in its transparent state, is, as I have already surmised, a tolerable conductor of electricity.

I will now venture to offer such an explanation of the electrical phænomena of effluent steam, as I conceive to be most consonant with the experiments $I$ have described in this and my preceding communication.

Independently of the experimental proofs which have been adduced of the neutral state of the steam up to the instant of its transformation into an opake vapour, the water and the steam must be so thoroughly intermixed in the boiler of a locomotive engine, as to render it impossible for the steam to become electrified with positive electricity without immediately imparting it to the water.

I assume, 'then, as a fact, established both by reason and experiment, that the steam is in a neutral state in the boiler; and I think I am equally supported in saying, that it does not exhibit positive electricity, after leaving the boiler, so long as it retains its aeriform nature.

We learn from experiment that a development of negative electricity in the boiler accompanies the emission of the steam; and since the negative development in the boiler is obviously independent of the subsequent condensation of the steam, it follows, that if the effluxion of the steam could be effected without permitting any condensation to take place, we should then have a development of negative electricity in the boiler without any simultaneous development of positive electricity ; and in like manner if the ejected steam were subsequently condensed into water, we should then have a liberation of positive electricity without a concomitant liberation of negative electricity.

These conclusions are entirely incompatible with the theory of two electric fluids, but are quite reconcileable with the hypothesis of a single fluid. It seems perfectly rational and consistent with analogy to suppose, that the immense augmentation of volume which takes place when water expands into steam of any ordinary density, should occasion a greatly increased capacity for electricity; and consequently, that the quantity of electricity which suffices to produce a neutral or saturated state in water, should be quite inadequate to sustain that condition when the water is converted into steam. Upon this supposition the steam as it forms in the boiler will absorb electricity from the adjacent conductors in 
order to acquire a neutral or saturated state, and when by condensation it again becomes water, the electricity thus absorbed will necessarily be set free; and hence the positive electricity which we find in the jet.

Upon the same principle, if the boiler be insulated, the water, the boiler, and the uncondensed steam, will all be rendered negative, provided the steam be permitted to escape, but not otherwise; for if the steam be confined within the limits of the boiler, the evaporation will not be attended with any increase of volume, and the absorption of electricity will in consequence be prevented. In all these respects the theory exactly accords with observation.

I am bound, however, to admit that the explanation which I have here advanced, involves certain conditions which appear somewhat at variance with experiment. In the first place the condensation of a given weight of low-pressure steam ought, if the absorption of electricity depends upon increase of volume, to liberate more positive electricity than the condensation of an equal weight of high-pressure steam; and in the second place, the expansion of steam from one degree of density to another should, on the same principle, be accompanied by a development of negative electricity. Notwithstanding, however, what has been advanced in favour of high-pressure steam containing more electricity than steam of low density, I think it quite possible that the reverse of this may be the fact; for it is not at all improbable that a lowpressure jet may conduct so large a portion of its electricity back again to the boiler as to make it appear to liberate less electricity than a high-pressure jet, while in reality it may develope a great deal more. It is quite reasonable to suppose that the conducting power of steam should be increased by rarefaction; and besides, in order to make a fair comparison between the quantities of electricity liberated by two jets of steam, it is indispensable that they should discharge equal weights in equal times, and to effect this condition it is necessary to discharge a much larger volume when the steam is of low pressure, than when it is of great density, and by so doing we unavoidably increase the quantity of unvaporized water swept out of the boiler in conjunction with the steam, and thus improve the communication between the jet and the boiler, and at the same time cause a considerable dispersion of the electricity.

With regard to expansion producing negative electricity, I have certainly never detected such a result; but I much question whether in any of the above experiments expansion was effected without an aqueous condensation sufficient to 
produce a countervailing effect; or the insulation was ever sufficiently perfect to prevent feeble negative electricity being carried off, or overwhelmed by the positive electricity developed in the jet.

Mr. Nicholson has zealously cooperated with me in the experiments I have described, and it is our intention to make a further attempt to clear up the difficulties which still embarrass the subject.

The limits of this letter will not permit me at present to enter upon any discussion on Dr. Schaf haeutl's interesting paper which appeared in your last publicatlon.

Newcastle-upon-Tyne, Dec. 19, 1840,

Wm. Geo. Armstrong.

XIII. Proceedings of Learned Societies. ROYAL SOCIFTY.

Anniversary Address of the Marquis of Northampton, President, Gentramen, November 30, 1840.

$\mathrm{N}$ addressing you at the termination of this, the second year that I I have had the honour of presiding over your Society, my first duty is to return my thanks to those gentlemen whom you have nominated to be my Council. They have rendered an onerous duty comparatively light and easy by their unremitting attendance and zeal ; and have, as I trust, prevented your affairs from suffering from any incompetency on my part. In making my report of the transactions of the last year, I know of nothing to regret, except the loss of some of our valued Associates, who between the end of last November and the present time have paid the debt of nature.

Among the new members enrolled in our body, it will perhaps be right to mention the name of the Bishop of Norwich, as being President of the Linnean Society, one of the oldest branches that may be considered as thrown off from our parent stem. Also that of the Duke of Richmond, as President of the two newest Associations founded for the promotion of science, the Royal Agricultural and Botanical Societies. We have one new member of still higher rank, who has honoured us by becoming one of our Fellows, H. R. H. Prince Albert, the consort of our beloved Queen and Patroness. As your organ, Gentlemen, I will venture to say that you duly appreciate the honour conferred on yourselves; at the same time while His Royal Highness gratifies us by joining our body, we entertain no doubt that he does so from the just conviction that the patronage and advancement of science are national objects of the deepest importance.

The Antarctic Expedition, to whose departure I adverted in my last year's Address, is, I trust, now successfully pursuing its carcer of scientific research. Already a portion of the fruits of its labours has reached us, and promises an abundant and valuable harvest. The fixed Magnetic Observatories on the territories of Her Majesty are now also in full operation; while foreign powers have given us 